\title{
Amino Silane, Vinyl Silane, TESPD, ZS(TESPD/Zinc Complex) Effects on Carbon Black/Clay Filled Chlorobutyl Rubber(CIIR) Compounds Part I: Effects on Hard Clay/Carbon Black Filled Compounds
}

\author{
Kwang-Jea Kim^ \\ Institute of Polymer Engineering, The University of Akron, Akron, OH 44325-0301 \\ Department of Polymer Sci. \& Eng., Gyeongsang National University, Jinju, Korea 660-701 \\ ‘e-mail:kkim@uakron.edu \\ (Received February 3, 2009; Accepted June 2, 2009)
}

\begin{abstract}
Various silanes, amino silane, vinyl silane, TESPD, and ZS (TESPD/zinc soap complex), are added into chlorinated isobutylene-isoprene copolymer (CIIR)/hard clay/carbon black (CB) compound and they are investigated with respect to the vulcanization characteristics, the processability, and the mechanical properties. In hard clay/CB filled system, only ZS silane added compound shows both lower Mooney viscosity and extrusion torque while vinyl silane added compound showed only a lower extrusion torque. All the ZS added compounds showed the lowest viscosity among them. The silane added compounds showed an increased modulus. In 'fatigue to failure' count test, the ZS added compound showed superior counts compared to other silane (amino, vinyl, TESPD) added compounds. The mechanical properties were significantly increased when the S2 and ZS were added into CIIR/hard clay/CB compound. The ZS added compounds showed a significant improvement on elongation modulus.
\end{abstract}

Keywords : CIIR/Silane/Hard Clay/Carbon Black Compound, Silane Additives, Processability, Mechanical Property

\section{Introduction}

The chlorinated isobutylene-isoprene copolymers (CIIR) are used for various applications such as tubeless tire innerliners, radial tire sidewalls (white/black), innertubes, tire curing bags, oil resistance automotive dynamic parts, heat and fatigue resistance goods, pharmaceutical closures, conveyer belts, steam hose compounds, gaskets, automotive windshield sealing tape and adhesive due to their good low gas permeability, wear, traction, dynamic flex, weathering (against for ozone, and UV), chemical/heat, damping, tack, reversion resistance and biological inertness. Crawford and Morrissey of B. F. Goodrich Company first patented the modification of butyl with small amounts of halogen[1]. Later, chlorination of butyl was studied by Baldwin and Thomas[2] and Baldwin et al[3] from Exxon Chemicals[4]. CIIR is often blended with other rubbers such as natural rubber (NR), styrene butadiene rubber (SBR), ethylenepropylene-diene terpolymer (EPDM), polychloroprene (CR), brominated isobutylene-isoprene copolymers (BIIR), and butyl rubber (IIR) etc. due to their similar backbone chains. Scheme 1 illustrates the structure of IIR, BIIR and CIIR. CIIR and BIIR show similar vulcanizate stability in various vulcanization systems; however, they show differences in chemical reactivity of the two halogens. The bond energy of $\mathrm{C}-\mathrm{Cl}$ bond energy is $79 \mathrm{kcal} / \mathrm{mole}$ while that of the $\mathrm{C}-\mathrm{Br}$ bond is $66 \mathrm{kcal} / \mathrm{mole}$. Thus BIIR is more reactive than CIIR i.e. CIIR has longer scorch time and better storage stability[4].

When SBR is blended with CIIR, as the concentrations of CIIR are increased, rebound values are decreased linearly and traction increased linearly; however treadwear decreases [5]. When CIIR is blended in NR/BR carbon black filled compounds, it shows a lower hysterisis and equal or better<smiles>[Y]CC=C(C)CC([3H])(C)C(C)(C)CC</smiles>

(a)<smiles>[X]C(CCCCC(C)(C)CC)C(=C)CC</smiles>

(b)

Scheme 1. (a) Isobutylene-isoprene rubber (IIR), (b) Halogenated isobutylene-isoprene rubber (CIIR $(\mathrm{X}=\mathrm{Cl})$ and BIIR $(\mathrm{X}=\mathrm{Br})$ ). 
wet traction[6]. CIIR/SBR blend gives a good grip and durability in high speed running tires[7]. CIIR tend to show a good wet traction; however shows a high abrasion loss independent of $\mathrm{T}_{\mathrm{g}}$ or tand values at $0^{\circ} \mathrm{C}[8]$. When CIIR is blended with $\mathrm{NR}$ the $\tan \delta$ values at $0^{\circ} \mathrm{C}$ and at $60^{\circ} \mathrm{C}$ increases[9].

There has been few researches on halogen atom containing elastomer compounds because the volume of consumption of those materials are relatively small compared to large quantity consuming elastomers such as NR, SBR, EPDM, and NBR etc.

Processing additives are used for improving processibility without sacrificing mechanical properties of the compound $[10,11]$. Authors previously showed effects of various processing additives in halogen atom containing elastomer compounds including polychloroprene elastomer (CR) and fluorocarbon elastomers (FKM)[12].

In this research, various silanes, amino (SCA1100), vinyl (SCA972), TESPD (SCA985 or S2), and ZS were tested in carbon black/hard clay (Suprex) filled chlorobutyl rubber (CIIR) innerliner compound with respect to the vulcanization properties, the processability, and the physical properties of the compounds. The rheological properties and mechanical properties were measured and compared with other silane added clay compounds.

\section{Experimental}

\subsection{Materials}

The silanes used in this study were amino (SCA-1100), vinyl (SCA-972), and sulfur (SCA985 bis(triethoxysilylpropyl) disulfide (TESPD) (S2)), which are obtained from Struktol. And ZS (TESPD/zinc soap complex) was prepared in our laboratory. The main chemical structures of each are shown in Fig. 1. Here we present the level of silane (S2) in the ZS compound. The TESPD level of the ZS used was the same level with other silanes tested. Structures of silanes used are summarized in Scheme 2. The elastomer used was chlorobutylene-isoprene rubber (CIIR), which was supplied by an Exxon Chemical the brand name of CB1066. The filler used was N774 (SRF-HM NS), which has BET $29\left(\mathrm{~m}^{2} /\right.$ g) product of Cabot. Various additives, including activators ( $\mathrm{ZnO}$, stearic acid), Maglite K (magnesium oxide, scorch retarder, activator, vulcanizer, acid acceptor, stabilizer, UV screener), processing aid, plasticizer, dispersing aid, (Circosol 4240), homogenizer (40MS, aromatic and aliphatic hydrocarbon chain mixture), extender (Suprex (hydrous aluminum silicate, hard clay), median particle diameter $0.3 \mu \mathrm{m}$, BET $22 \sim 26\left(\mathrm{~m}^{2} / \mathrm{g}\right.$ ), Allied whiting (calcium carbonate, mean particle size $15.5 \mu \mathrm{m}$ ), curing agent (Sulfur), and accelerator (MBTS (2,2'-dithiobisbenzothiazole)), were used for general rubber compound. The information on the materials used in the study is summarized in Table 1.

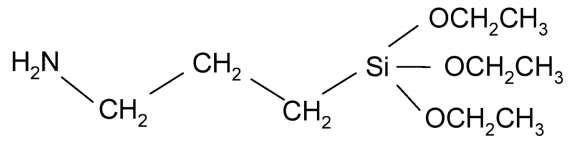

(a) SCA-1100 ( $\gamma$-Aminopropyltriethoxysilane)

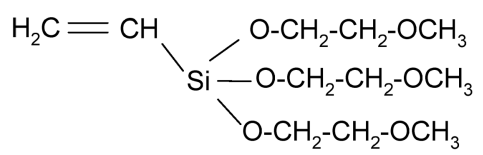

(b) SCA-972 (Vinyl-tris(2-methoxyethoxy)silane)<smiles>CCO[Si]1(OCC)CCCSSCCC[Si](OCC)(OCC)OCC1</smiles>

(c) SCA-985 (Bis(triethoxysilylpropyl)disulfide) (TESPD (S2))

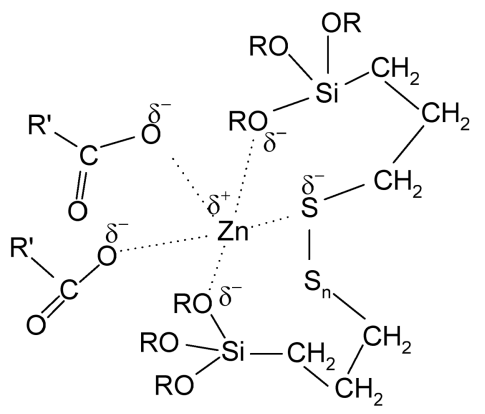

(d) ZS where $\mathrm{n}$ is one, -OR is alkoxy group, and $\mathrm{R}^{\prime}$ is $\mathrm{C}_{6}-\mathrm{C}_{20}$

Scheme 2. Chemical structure of silanes used.

\subsection{Mixing}

Banbury internal mixer (BR 1600) was used for masterbatch mixings (MB1 and MB2) of rubber and additives (batch: the product of one mixing operation). In the Calcite, hard clay, and soft clay /CIIR/additive system amino-, vinyl-, sulfur-(S2), S2/ $\mathrm{H}_{2} \mathrm{O}(\mathrm{W}) / \mathrm{EtOH}(\mathrm{E}), \mathrm{S} 2 /$ zinc silanes were added. The silane level of each compound was 3 phr. The S2 concentration in ZS (7.5 phr) was $3 \mathrm{phr}$ (S2: $40 \%$, zinc soap carrier: $60 \%$ ). All the materials with the same ingredients were added in masterbatch 1 (MB1) and discharged (dropped) at $300 \mathrm{sec}$ mixing. At second pass mixing (MB2), the CIIR compounds were further mixed with sulfur and MBTS for $120 \mathrm{sec}$. The total mixing times of the compounds were the same for $7.0 \mathrm{~min}$ each. The fill factor, ram pressure and rotor speed was fixed at $80 \%$ to eliminate air in stock to 
Table 1. Materials used in this Study

\begin{tabular}{cccc}
\hline Usage & Trade name & Supplier & notes \\
\hline Rubber & Chloro Butyl 1066 & Exxon Chemical & CIIR \\
Filler & N774 (SRF-HM NS) & Cabot & Carbon black $29\left(\mathrm{~m}^{2} / \mathrm{g}\right)$ \\
Extender & Allied Whiting Suprex & Akrochem Kentuckey-Tennessee Clay Co. & Calcite Hard Clay \\
Activator & ZOCO & Zochem & Zinc Oxide \\
Activator & Stearic acid & Harwick Standard & Magnesium Oxide \\
Retarder, Activator & Maglite K & CHP Solutions Co. & Amino silane \\
Homogenizer & $40 M S$ & Struktol & Vinyl silane \\
Silane & SCA1100 & Struktol & TESPD \\
Silane & SCA972 & Struktol & TESPD/zinc soap compound \\
Silane & SCA985 & Struktol & \\
Silane & ZS & GNU (Lab. Mat.) & \\
Accelerator & MBTS & Pennwalt Co. & \\
Vulcanizer & Sulfur & & \\
\hline
\end{tabular}

${ }^{1}$ Chlorinated Isobutylene-Isoprene copolymer

${ }^{2} \mathrm{ZS}$ : TESPD/zinc soap/carrier compound

${ }^{3}$ MBTS: 2,2'-dithiobisbenzothiazole

Table 2. Mixing Formulations and Procedure on Hard Clay/Carbon Black/CIIR Compounds Formulation

\begin{tabular}{|c|c|c|c|c|c|c|c|}
\hline 1st Pass Ingredient & Calcite (Cal) & Suprex (S) & $\mathrm{S} / \mathrm{A}$ & $\mathrm{S} / \mathrm{V}$ & $\mathrm{S} / \mathrm{S} 2$ & $\mathrm{~S} / \mathrm{S} 2 / \mathrm{W} / \mathrm{E}$ & $\mathrm{S} / \mathrm{ZS}$ \\
\hline CB1066 & 100.0 & 100.0 & 100.0 & 100.0 & 100.0 & 100.0 & 100.0 \\
\hline N774(SRF-HM NS) & 50.0 & 50.0 & 50.0 & 50.0 & 50.0 & 50.0 & 50.0 \\
\hline Maglite K & 0.25 & 0.25 & 0.25 & 0.25 & 0.25 & 0.25 & 0.25 \\
\hline Circosol 4240 & 8.0 & 8.0 & 8.0 & 8.0 & 8.0 & 8.0 & 8.0 \\
\hline 40MS & 7.0 & 7.0 & 7.0 & 7.0 & 7.0 & 7.0 & 7.0 \\
\hline Stearic Acid & 2.0 & 2.0 & 2.0 & 2.0 & 2.0 & 2.0 & 2.0 \\
\hline Allied Whiting $\left(\mathrm{CaCO}_{3}\right)$ & 30.0 & - & & - & - & - & - \\
\hline Suprex (Hard clay) & - & 30.0 & 30.0 & 30.0 & 30.0 & 30.0 & 30.0 \\
\hline SCA1100 (Amino S) & - & - & 3.0 & - & - & - & - \\
\hline SCA972 (Vinyl S) & - & - & - & 3.0 & - & - & - \\
\hline SCA985 (TESPD) & - & - & - & - & 3.0 & 3.0 & - \\
\hline $\mathrm{H}_{2} \mathrm{O} / \mathrm{EtOH}(\mathrm{W} / \mathrm{E})$ & - & - & - & - & - & 7.5 & - \\
\hline ZS (TESPD/Zn soap com.) & - & - & - & - & - & - & $7.5(3.0 / 4.5)$ \\
\hline $\begin{array}{l}\text { 2nd Pass } \\
\text { Zinc Oxide }\end{array}$ & 3.0 & 3.0 & 3.0 & 3.0 & 3.0 & 3.0 & 3.0 \\
\hline MBTS & 1.5 & 1.5 & 1.5 & 1.5 & 1.5 & 1.5 & 1.5 \\
\hline Sulfur & 0.5 & 0.5 & 0.5 & 0.5 & 0.5 & 0.5 & 0.5 \\
\hline
\end{tabular}

prevent the stock from oxidation, the rap pressure was set to $30 \mathrm{psi}$ and mixing speed was $60 \mathrm{rpm}$, respectively. The mixing formulations and procedures are included in Table 2.

\section{Mixing Procedure}

1st stage mixing (Master batch mixing (MB1)) : Fill factor $0.8,60 \mathrm{rpm}$ and $30 \mathrm{psi}$

Starting Mixer Temp : $70^{\circ} \mathrm{C}\left(158^{\circ} \mathrm{F}\right)$

1. Add rubber

2. Mix for $90 \mathrm{sec}$

3. Add $\mathrm{CB}$ and other additives

4. Mix for $150 \mathrm{sec}$ and sweep.
5. Sweep at $210 \mathrm{sec}$

6. Drop at $300 \mathrm{sec}\left(\right.$ or $140^{\circ} \mathrm{C} / 284^{\circ} \mathrm{F}$ )

2nd stage mixing (MB2) : $60 \mathrm{rpm}$ and $30 \mathrm{psi}$

Starting Mixer Temp : $65^{\circ} \mathrm{C}\left(150^{\circ} \mathrm{F}\right)$

1. Add MB1 and curatives

2. Drop at $120 \mathrm{sec}\left(\right.$ or $\left.100^{\circ} \mathrm{C}\left(212^{\circ} \mathrm{F}\right)\right)$.

\subsection{Mooney Viscosity Measurement}

Mooney viscosities were measured as a function of apparent shear rate at $2 \mathrm{rpm}$ and $\mathrm{ML} 1+4$ at $100^{\circ} \mathrm{C}$ according to ASTM D1646. The rotor diameter of the shearing disc rheometer was $38.1 \mathrm{~mm}$ and the thickness of the rotor was 
$5.5 \mathrm{~mm}$. The machine we used for measuring Mooney viscosity was brand name Mooney Viscometer 2000 (MV 2000) manufactured from Alpha Technology. The shear rate at the outer radius of the shearing disc could be expressed as follows[13,14]:

$$
\gamma(R)=\frac{R \Omega}{H}
$$

where $R$ is the radius of rotating disc, $\Omega$ the rotor rotation rate, $H$, the distance between the disc surface and the stationary housing.

\subsection{Cure Rheometer Test}

Oscillating disc cure rheometer (Model Rheotec) manufactured from Tech Pro Inc. was used for measuring vulcanization and reversion resistance property of the compounds in a pressurized rotational rheometer with a biconical rotor following ASTM D 2084 at $177^{\circ} \mathrm{C}$. The oscillation frequency was 100 cycles/min $(1.66 \mathrm{~Hz})$ with amplitude of $3^{\circ}$. Minimum torque $\left(\mathrm{M}_{\mathrm{L}}\right)$, maximum torque $\left(\mathrm{M}_{\mathrm{H}}\right)$, torque rise $\left(\mathrm{M}_{\mathrm{H}}-\mathrm{M}_{\mathrm{L}}\right)$, scorch (premature vulcanization of a rubber compound) time (Ts-2), cure time (Tc-90), and reversion (deterioration of vulcanizate properties that may occur when vulcanization time is extended beyond the optimum) resistance time (T-2) were measured.

\subsection{Screw Extrusion}

Single Screw Lab Exrtruder (SSE) manufactured by C. W. Brabender Instruments, Inc. (CWB) attached with roll feeder (Model 1513) was used and data were obtained from a PC attached to CWB at the time of extrusion of the compounds. The drive type of the extruder for SSE was Plasti-Corder PL2100 manufactured by CWB. The length/diameter (L/D) ratio of the screw was 15:1 (barrel diameter $19 \mathrm{~mm}$ ) with compression ratio of three-to-one $(3: 1)$. The processing temperature and screw speed were set to $100^{\circ} \mathrm{C}$ and $25 \mathrm{rpm}$, respectively. Garvey type ASTM Extrusion Die (see ASTM D 2230-88) was attached at the exit of the screw. The pressure buildup (psi) of each compound at the exit of the die was measured.

\subsection{Tensile Test}

An Instron tensile tester (Model 4201) with data acquisition system was used to obtain tensile test data of dumbbell specimen. The average of three specimens was obtained following the ASTM D 412-87 method. This instrument meets the ASTM E4 and measures mechanical properties of the materials, which was a table mounted units consisting of loading frame and control console as separate assemblies. The modulus $(\mathrm{Pa})$ of each compound was measured at $300 \%$ elongation. The average thickness and width of the specimens were $2.2 \mathrm{~mm}$ and $6.3 \mathrm{~mm}$, respectively.
The mill direction (MD) specimen and transverse direction specimen (TD) were prepared and the tensile moduli of each compound were measured. The test specimen was in the shape of a dumbbell with dimensions; width, $4.0 \mathrm{~mm}$; thickness, $1.4 \mathrm{~mm}$; and total length, $78.5 \mathrm{~mm}$.

\subsection{Tear Resistance Test}

The tear resistance test data were obtained from the die C shaped specimens measured following ASTM D 624 method. Instron Universal Testing Instruments Model 4201, which described above was used obtaining test data. The tear resistance $(\mathrm{N} / \mathrm{mm})$ and maximum load $(\mathrm{kN})$ of each specimen was measured. The average value out of three specimens was obtained. The thickness of the specimens was average $2.2 \mathrm{~mm}$, and the width of the specimens at D-rad was average $12.7 \mathrm{~mm}$.

\subsection{Fatigue to Failure Tester}

The Monsanto Fatigue to Failure Tester (Model number; FF-1) was used for measuring of the fatigue life of cured specimens according to the ASTM D 4482-85 method. Dumbbell shape samples are subjected to a repeated strain cycle and the numbers of cycles to failure were recorded. Com-parisons at equal strain-energy input eliminate differences between specimens, which arise solely from differences in modulus. Fatigue lives are determined at a fixed extension ratio $100 \%$ and the numbers at failure were recorded for comparison of specimens. The test specimen is mounted in the grips of crosshead, one end is consisting of the dynamic bar and the other end is fixed static bar. Upper dynamic bar is axially circulatory oscillating at a constant speed of $1.7 \pm 0.17 \mathrm{~Hz}$. The amplitude of the moving part was $60.0 \mathrm{~mm}$. The initial extension pressure applied on the cross section was $1560 \mathrm{~Pa}$. The test specimen was in the shape of a dumbbell with dimensions; width, $4.0 \mathrm{~mm}$; thickness, $1.4 \mathrm{~mm}$; and total length, $78.7 \mathrm{~mm}$ (including $6.35 \mathrm{~mm}$ diameter bead along each lengthwise edge; inner length is $66.0 \mathrm{~mm})$.

\section{Results}

Fig. 1 shows vulcanization curve of various silane (Amino, Vinyl, S2 (TESPD), S2/Water/Ethanol, and ZS) treated hard clay (Suprex) filled in CIIR matrix for inner liner compound. The Suprex (S) filled compound showed a lower curve than calcite filled compound. Addition of amino, S2, and S2/W/E silanes to Suprex did not lower the torque minimum $\left(\mathrm{M}_{\mathrm{L}}\right)$, and vinly silane added compound showed no significant effect on $\mathrm{M}_{\mathrm{L}}$ changes; however, the $\mathrm{ZS}$ added compound showed a significant reduction in $\mathrm{M}_{\mathrm{L}}$.

As the vulcanization time increased, the torque level of 


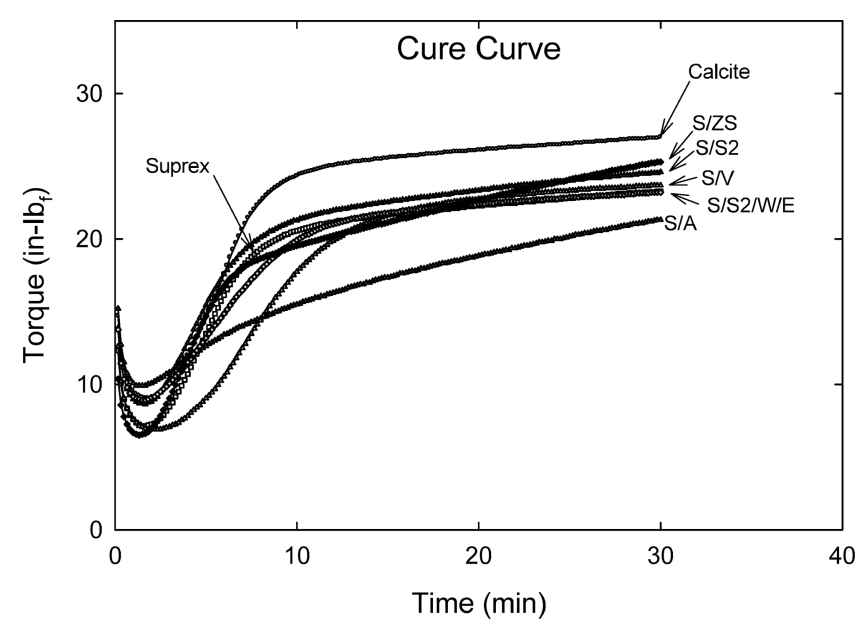

Fig. 1. Vulcanization curve of various silane (Amino, Vinyl, S2 (TESPD), S2/Water/Ethanol, and ZS) treated hard clay (Suprex) filled in CIIR matrix.

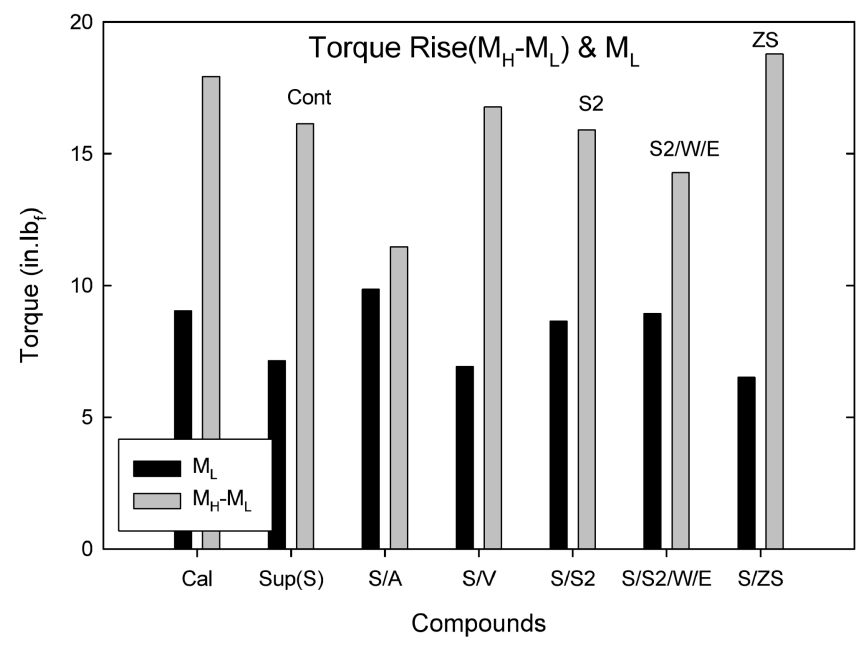

Fig. 2. Torque rise $\left(\mathrm{M}_{\mathrm{H}}-\mathrm{M}_{\mathrm{L}}\right)$ and torque minimum $\left(\mathrm{M}_{\mathrm{L}}\right)$ at $100^{\circ} \mathrm{C}$ for $30 \mathrm{~min}$.

each compound was changed. Among them, amino silane added compound showed steady increasing torque behavior, while other compounds showed delaying scorch behavior.

Fig. 2 shows torque rise $\left(\mathrm{M}_{\mathrm{H}}-\mathrm{M}_{\mathrm{L}}\right)$ and torque minimum $\left(\mathrm{M}_{\mathrm{L}}\right)$ measured from cure rheometer at $100^{\circ} \mathrm{C}$ for $30 \mathrm{~min}$. The Suprex filled compound showed a lower torque rise than calcite filled one. Addition of $\mathrm{ZS}$ only increased the torque rise significantly, and vinyl silane and S2/W/E added compounds showed no significant changes, and amino silane added compound showed a significant reduction in torque rise.

The Suprex (S) filled compound showed lower torqueminimum $\left(\mathrm{M}_{\mathrm{L}}\right)$ than calcite filled compound. Addition of amino silane, $\mathrm{S} 2$, and $\mathrm{S} 2 / \mathrm{W} / \mathrm{E}$ to Suprex slightly increased the torque minimum $\left(\mathrm{M}_{\mathrm{L}}\right)$, and vinly silane added compound showed no significant changes in $\mathrm{M}_{\mathrm{L}}$; however, the ZS added compound showed a reduction in $\mathrm{M}_{\mathrm{L}}$.

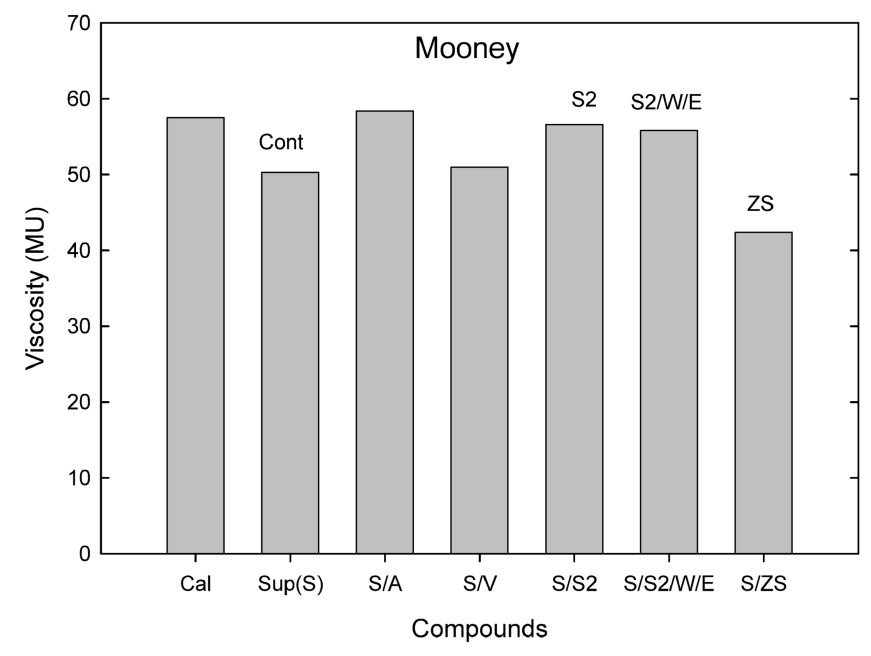

Fig. 3. Mooney viscosity $(\mathrm{ML1}+4)$ at $100^{\circ} \mathrm{C}$.

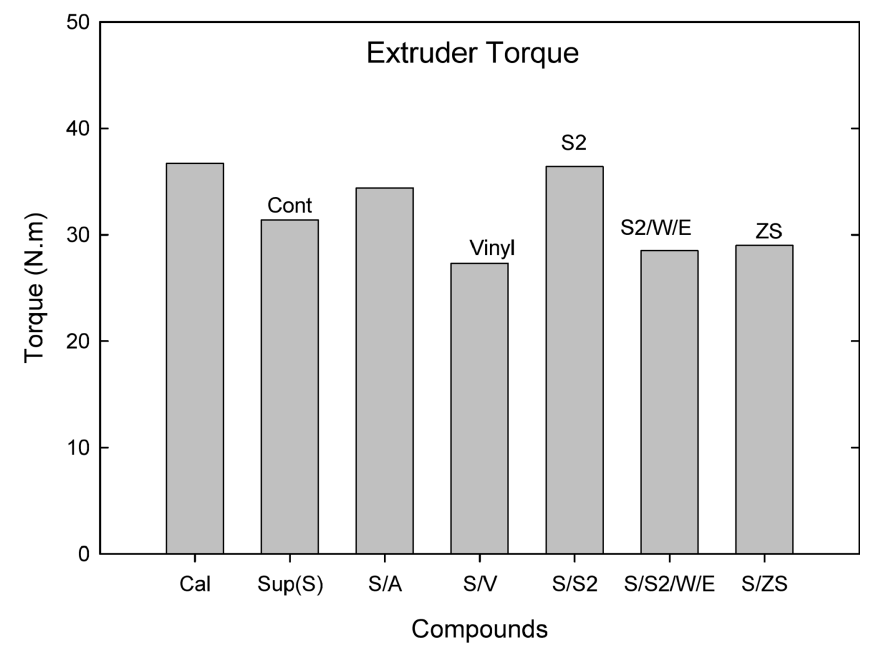

Fig. 4. Extruder torque buildup on the screw surface at $100^{\circ} \mathrm{C}$ and $25 \mathrm{rpm}$.

Fig. 3 represents Mooney viscosity (ML1+4) measured from a Mooney viscometer at $100^{\circ} \mathrm{C}$. It showed the same trend observed from the vulcanization curve of the $\mathrm{M}_{\mathrm{L}}$. Addition of amino silane, S2, and S2/W/E did not lower the $\mathrm{M}_{\mathrm{L}}$, and vinly silane added compound showed no significant effect on $\mathrm{M}_{\mathrm{L}}$ changes; however, the $\mathrm{ZS}$ added compound showed a significant reduction in $\mathrm{M}_{\mathrm{L}}$.

Fig. 4 shows extruder torque buildup on the screw surface measured from single screw extruder at $100^{\circ} \mathrm{C}$ and $25 \mathrm{rpm}$. Addition of amino and S2 silanes to Suprex increased the torque buildup; however, vinyl silane, $\mathrm{S} 2 / \mathrm{W} / \mathrm{E}$ and $\mathrm{ZS}$ added compounds showed a significant reduction in torque buildup on the screw.

Fig. 5 shows extruder pressure buildup in the extruder barrel measured from single screw extruder at $100^{\circ} \mathrm{C}$ and 25 $\mathrm{rpm}$. Addition of amino- and S2 silanes to Suprex increased the torque, and vinyl silane and $\mathrm{S} 2 / \mathrm{W} / \mathrm{E}$ added compounds 


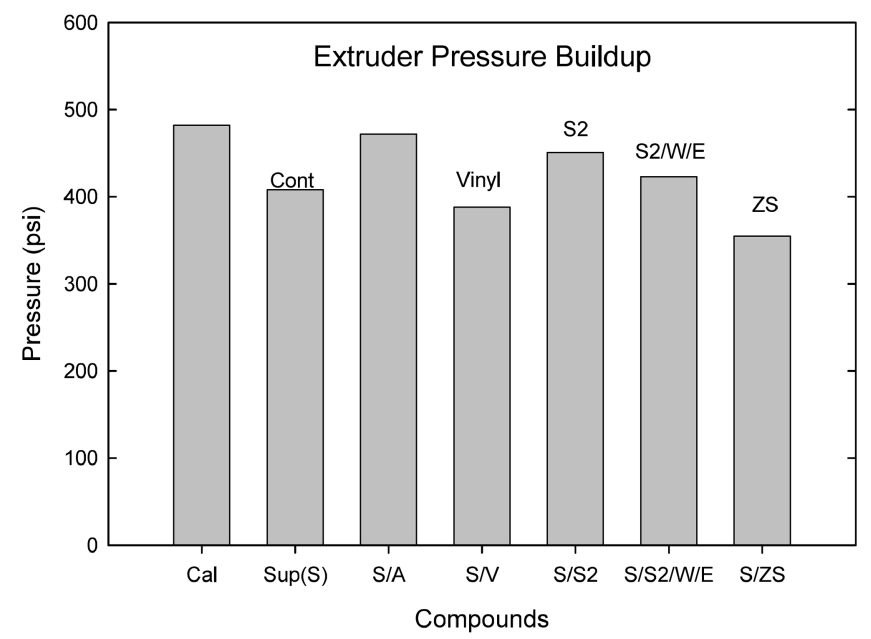

Fig. 5. Extruder pressure buildup in the extruder barrel at $100^{\circ} \mathrm{C}$ and $25 \mathrm{rpm}$.

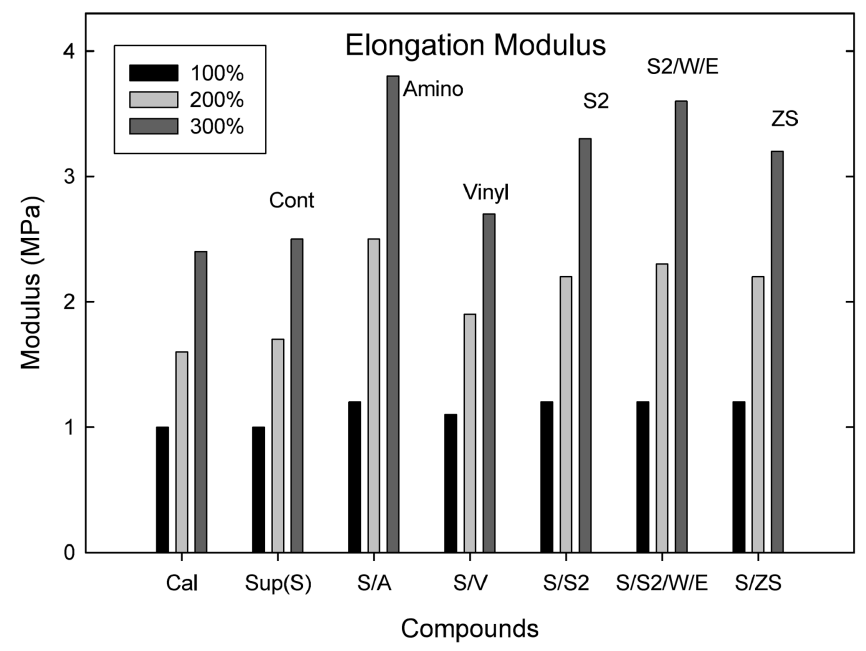

Fig. 6. Elongation modulus (These samples were cured 6 days after MB2).

showed no significant changes; however, the ZS added compounds showed a significant reduction in pressure buildup on the extruder die end.

Fig. 6 shows an elongation modulus measured from an Instron tensile tester at 100, 200, and 300\% elongation. The Suprex filled compound showed a slightly higher elongation modulus than calcite filled compound. Addition of silanes (amino, vinyl, S2, S2/W/E, and ZS) to Suprex increased the elongation modulus. Among them amino, S2, S2/W/E, and $\mathrm{ZS}$ added compounds showed a significant increase in elongation modulus; however, vinyl silane added compounds showed a slight increase in elongation modulus.

Fig. 7 shows a die $\mathrm{C}$ tear tension measured from an Instron tensile tester. The Suprex filled compound showed a higher tear tension $(\mathrm{N} / \mathrm{mm})$ than the calcite filled compound. Addition of silanes (vinyl, S2, and ZS) to the Suprex increased the elongation modulus; however, amino- and S2/W/E silane

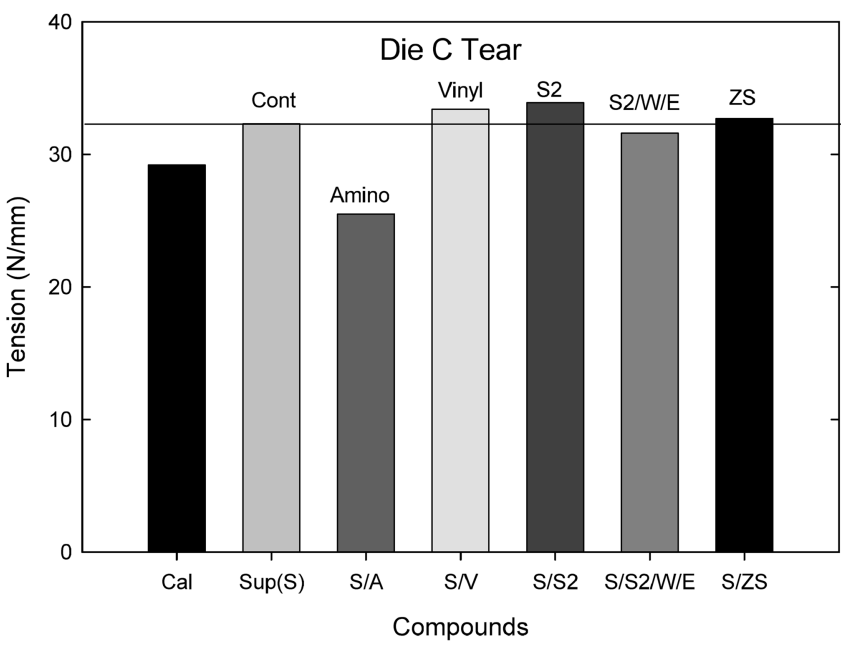

Fig. 7. Die $C$ tear (These samples were cured 6 days after MB2).

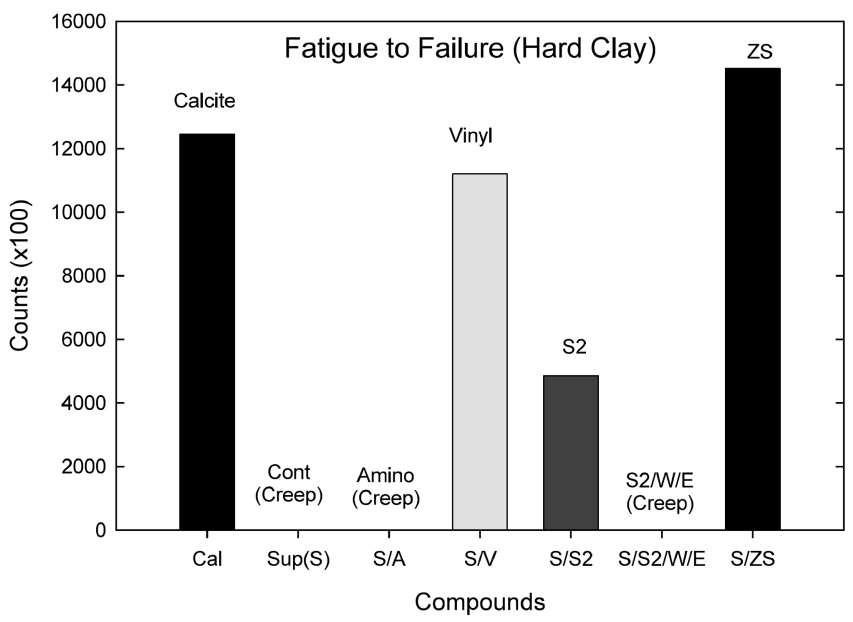

Fig. 8. Fatigue to failure.

added compounds showed a decrease in tear tension.

Fig. 8 shows fatigue to failure results. The Suprex filled compound showed a creep behavior, which resulted in zero count. Only ZS silane added compound showed a significant improvement in counts. Amino silane and S2/W/E compounds also showed a creep behavior. Vinyl silane and S2 added compounds did not show increased counts.

The results are summarized as follow; Processability was increased by addition of vinyl, S/S2/W/E and ZS silanes. In Mooney viscosity measurement, the $\mathrm{ZS}$ added compounds showed a lower viscosity than the Control (Suprex), while vinyl silane added one showed a slight increase in Mooney viscosity. Among them the ZS added compound showed the best overall. Elongation modulus was increased by the addition of silanes (amino, vinyl, S2, S2/W/E and ZS). In tear tension measurement, the amino and $\mathrm{S} 2 / \mathrm{W} / \mathrm{E}$ added compounds showed a lower tension than the Control, while vinyl, S2, and ZS silane added one showed an increased tear tension. Among them the vinyl silane, S2, and ZS added 
Table 3. Summary of Figures Compared with Suprex (S) Filled CIIR Compound

\begin{tabular}{|c|c|c|c|c|c|c|c|c|c|}
\hline & $\begin{array}{c}\text { Mooney } \\
\text { (MU) } \\
(-)\end{array}$ & $\begin{array}{c}\text { Extru. } \\
\text { Torq. } \\
(-)\end{array}$ & $\begin{array}{c}\text { Extru. } \\
\text { Press. (-) }\end{array}$ & $\begin{array}{c}\text { Torque rise } \\
\mathrm{M}_{\mathrm{H}}-\mathrm{M}_{\mathrm{L}} \\
(+)\end{array}$ & $\begin{array}{c}\text { Mod } \\
300 \% \\
(+)\end{array}$ & $\begin{array}{c}\text { Tear } \\
\text { (die C) } \\
(+)\end{array}$ & $\begin{array}{l}\text { Fatig. to } \\
\text { failure } \\
(+)\end{array}$ & $\begin{array}{c}\text { Edge } \\
1 \text { (poor) } \\
10(\text { good })\end{array}$ & $\begin{array}{c}\text { Surface } \\
\mathrm{A}(\text { good }) \\
\mathrm{E}(\text { poor })\end{array}$ \\
\hline Hard S/Amino & + & + & + & - & + & - & - & 8 & A \\
\hline Clay S/Vinyl & $\sim$ & - & - & + & + & + & creep & 8 & A \\
\hline $\mathrm{S} / \mathrm{S} 2$ & + & + & + & - & + & + & - & 8 & A \\
\hline $\mathrm{S} / \mathrm{S} 2 / \mathrm{WE}$ & + & - & $\sim$ & - & + & - & creep & 8 & A \\
\hline $\mathrm{S} / \mathrm{ZS}$ & - & - & - & + & + & + & + & 7 & A \\
\hline
\end{tabular}

$(+)$ : increase, (-): decrease

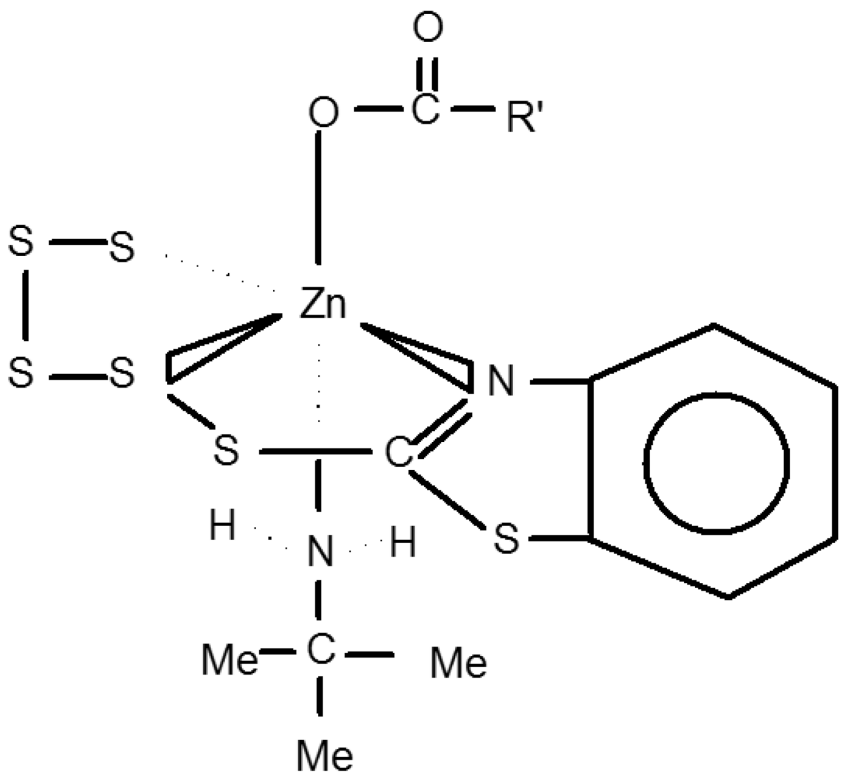

\section{R' = Alkyl, Brabched Alkyl, Aromatic Alkyl}

Fig. 9. Zinc ion effect on sulfur ring opening reaction mechanism at pre-vulcanization intermediate state[20].

compound showed the highest overall. Results are summarized in Table 3. Only the ZS and vinly silane added compounds showed both improvements in processability and mechanical properties.

\section{Discussion}

The researches on natural rubber based compounds have been widely studied[15-20]; however, there have been few researches on CIIR matrix system[12]. Furthermore the effects of zinc ion surfactant have almost exclusively done by authors[19,20].

The zinc ion containing compound (ZS) showed both a better processability and mechanical properties compared to the $\mathrm{S} 2$ ones at low concentration. Alkyl group attached on a zinc ion played as a processing promoter between polymer chains and zinc ion acted as a reaction promoter between

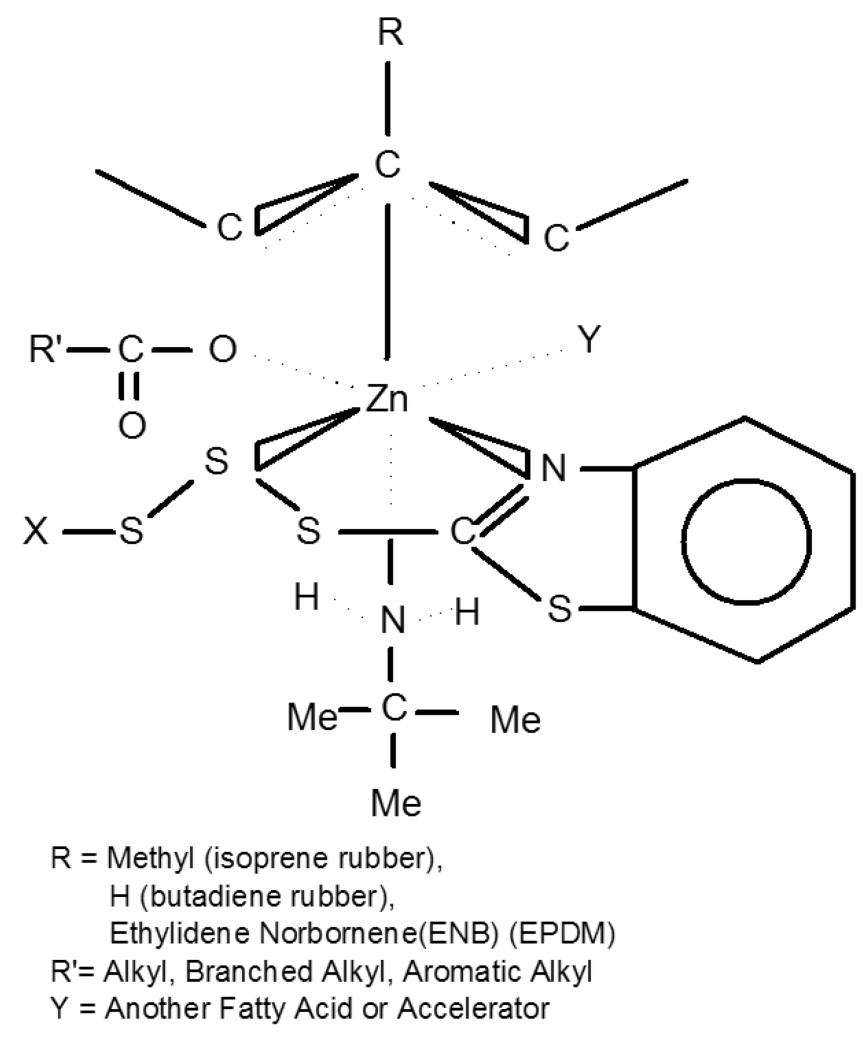

Fig. 10. Zinc ion effect on cross-linking intermediate ( $p$ allyl complex)[20].

sulfur in TESPD and double bonds in polymer chain. The zinc ion in ZS effectively helped a formation of a strong 3dimensional network structure between hard clay and CIIR via expansion and contraction mechanism[20]. The zinc ion present in the ZS helped a covalent bonding formation between sulfur in TESPD and double bond in CIIR. This gives a strong three-dimensional network structure of the TESPD treated hard clay filled CIIR compound. The crosslinking mechanism with rubber matrix was result of sulfur ring opening mechanism via bi-pyramidal model. Kim[20] suggested a new mechanism to explain sulfur containing silane reaction with double bond in polymer chain with help of zinc ion. Examples for zinc ion effect on sulfur ring opening reaction and cross-linking formation are given in Fig. 9 and 10, respectively[20]. 


\section{Conclusions}

Various silanes (amino, vinyl, S2, S2/W/E and ZS) were added into hard clay (Suprex)/CB/ CIIR compound and their processabilities and mechanical properties were compared. It is concluded as followed. The vinyl silane and the $\mathrm{ZS}$ added compound showed positive results for improving processabilities and mechanical properties. Comparing the ZS and the vinyl silane, the $\mathrm{ZS}$ added one showed better processabilities and mechanical properties at the same silane level $3 \mathrm{phr}$.

\section{References}

[1] Crawford, R. A.; Morrissey, R. T. U.S. Patent 2,681,899 (June 1959); 2,698,041 (Dec. 1954); 2,720,479 (Oct. 1955).

[2] Baldwin, F. P.; Thomas, R. M. U. S. Patent 2,944,578 (July 1960).

[3] Baldwin, F. P.; Buckley, D. J.; Kuntz, I.; Robinson, S. B. Rubber and Plastic Age (London), 1961, 42, 500.

[4] Anonymous, "Chlorobutyl Rubber Compounding and Applications", Section 5, Exxon ${ }^{\circledR}$, Houston, TX, 10, 1989.

[5] Keller, R. C., Tire Sci. Technol. 1973, 1, 190.

[6] Hirakawa, H.; Ahagon, A. Tire Sci. Technol. 1982, 10, 16.

[7] Takiguchi, E.; Kikutsugi, T. (Bridgestone) U. S. Patent $4,945,964(8 / 7 / 90)$.
[8] Takino, H.; Nakayama, R.; Yamada, Y.; Kohjiya, S.; Matsuo, T. Rubber Chem. Technol. 1997, 70, 584.

[9] Garro, L.; Martin, M. (Pirelli) U. S. Patent 5,362,793 (11/8/94).

[10] White, J. L.; Kim, K. J. "Thermoplastic and Rubber Compounds: Technology and Physical Chemistry", Hanser Publisher, Munich, Cincinnati, 57, 2008.

[11] Gupta, R. K.; Kennel, E.; Kim, K. J. (Eds.) "Polymer Nanocomposites Handbook” CRC Press, Boca Raton, 45, 2009.

[12] Kim, K. J.; Vanderkooi, J.; Wasko, J.; Hensel, M. Automotive Elastomer Conference 2004 (AES-2004), Dearborn, MI, 2004, Paper No. 18.

[13] White, J. L. "Principle of Polymer Engineering Rheology", Wiley Inter-Science, New York, 79, 1990.

[14] White, J. L. "Rubber Processing: Technology, Materials, and Principles", Hanser Publishers, Cincinnati, 80, 1995.

[15] Kim, D. H.; Kim, H. M.; Lee, C. S.; Ahn, W. S.; Kim, J. H. Elastomer 2006, 41(2), 88.

[16] Kaang, S. Y.; Nam, K. T.; Hong, C. K.; Kae, K. H. Elastomer 2006, 41(3), 182.

[17] Park, H. S.; Woo, C. S. Elastomer 2007, 42(1), 32.

[18] Alex, R.; Kim, M. J.; Lee, Y. S.; Nah, C. Elastomer 2006, 41(4), 252.

[19] Kim, K. J.; Vanderkooi, J. Elastomer 2004, 39, 263.

[20] Kim, K. J.; Vanderkooi, J. Int. Polym. Process. 2002, 17(3), 192. 